tricks on endoaortic balloon clamping in these cases are described. The small dimensions of the aorta and the femoral vessels do not hamper the port-access technique. An accurate preoperative evaluation of the anatomy of the aorto-iliac and femoral arteries is mandatory, especially in these cases.

\section{References}

1. Grossi EA, Loulmet DF, Schwartz CF, Ursomanno P, Zias EA, Dellis SL, et al. Evolution of operative techniques and perfusion strategies for minimally invasive mitral valve repair. J Thorac Cardiovasc Surg. 2012;143:S68-70.
2. Modi P, Rodriguez E, Hargrove WC III, Hassan A, Szeto WY, Chitwood WR Jr Minimally invasive mitral video-assisted mitral valve surgery: a 12-year, 2-center experience in 1178 patients. J Thorac Cardiovasc Surg. 2009;137: 1481-7.

3. Ricci D, Pellegrini C, Aiello M, Alloni A, Cattadori B, D'Armini AM, et al Port-access surgery as elective approach for mitral valve operation in re-do procedures. Eur J Cardiothorac Surg. 2010;37:920-5.

4. Ricci D, Boffini M, Barbero C, El Qarra S, Marchetto G, Rinaldi M. Minimally invasive tricuspid valve surgery in patients at high risk. $J$ Thorac Cardiovasc Surg 2013. Epub ahead of print.

5. Preisman S, Keidan I, Perel A, Mishaly D. Anesthesia for port-access cardiac surgery in a pediatric population. J Cardiothorac Vasc Anesth. 2005;19: 626-9.

\title{
Endoscopic lung abscess drainage with argon plasma coagulation
}

\author{
Eric Goudie, MD, Jordan Kazakov, MD, Claude Poirier, MD, and Moishe Liberman, MD, PhD, Montreal, \\ Quebec, Canada
}

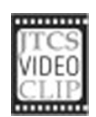

Video clip is available online.

Lung abscesses are most often caused by aspiration of oropharyngeal bacterium. Another cause is airway obstruction. ${ }^{1}$ Antibiotic therapy is the standard treatment approach, but it fails in $10 \%$ to $20 \%$ of cases. ${ }^{2}$ In such cases, alternative therapeutic options usually consist of percutaneous drainage or surgical resection. Endoscopic abscess drainage is another option, but this only has been described in a few case reports and case series.

This case report describes a novel technique for endoscopic lung abscess drainage with argon plasma coagulation. This technique was successfully performed on a patient with limited treatment options.

\section{CLINICAL SUMMARY}

We report the case of a 63-year-old woman who was referred for a left upper lobe (LUL) abscess. Seven years

\footnotetext{
From CHUM Endoscopic Tracheobronchial and Oesophageal Center (CETOC), University of Montreal, Montreal, Quebec, Canada.

Disclosures: Authors have nothing to disclose with regard to commercial support. Received for publication March 3, 2013; revisions received May 10, 2013; accepted for publication May 21, 2013; available ahead of print July 15, 2013.

Address for reprints: Moishe Liberman, MD, PhD, CHUM Endoscopic Tracheobronchial and Oesophageal Center (CETOC), Division of Thoracic Surgery, Centre Hospitalier de l'Université de Montréal, 1560 Rue Sherbrooke E, 8e CD, Pavillon Lachapelle, Bureau D-8051, Montreal, Quebec H2L 4M1, Canada (E-mail: moishe.liberman@umontreal.ca).

J Thorac Cardiovasc Surg 2013;146:e35-7

0022-5223/ $\$ 36.00$

Copyright (c) 2013 by The American Association for Thoracic Surgery http://dx.doi.org/10.1016/j.jtcvs.2013.05.031
}

previously, she had undergone curative intent chemoradiotherapy for LUL squamous cell carcinoma. After treatment, a cavity developed in the LUL, eventually reaching a size of $8.2 \times 4.4 \mathrm{~cm}$ and remaining stable on follow-up computed tomographic scans (Figure 1). Before referral, the patient had received a 1-year course of clarithromycin, rifampin (INN rifampicin), and ethambutol for Mycobacterium avium-intracellulare complex. After treatment, her preantibiotic symptoms of coughing, bronchorrhea, and fever returned, and she reported left pleuritic chest pain. She did not have leukocytosis. Bronchoscopy showed a new and complete obliteration of the left apicoposterior segment bronchus, and bronchoalveolar lavage culture results were negative. The patient was referred for attempt at reopening of the LUL bronchus and endoscopic abscess drainage.

Standard consent was obtained. The patient was placed under general anesthesia. A rigid bronchoscopy was performed, and a therapeutic flexible therapeutic bronchoscope was used through the rigid bronchoscope. A small amount of pus was found in the apical segment of the LUL, with no visible bronchial opening into either the apical or posterior segments. An endobronchial ultrasonographic radial miniprobe was used to confirm the absence of major blood vessels around the bronchus. A 3-mm opening was made to enter the cavity through the apical segment bronchus with a flexible argon plasma coagulation probe. Balloon dilatation was then used to widen the opening to $9 \mathrm{~mm}$. Bleeding was minimal and completely resolved with argon plasma coagulation. A large amount of pus was drained from the cavity, which was inspected and irrigated with saline solution. The cavity opening was left wide open for continuous spontaneous drainage. The procedure was completed in 12 minutes. The patient had postprocedural 


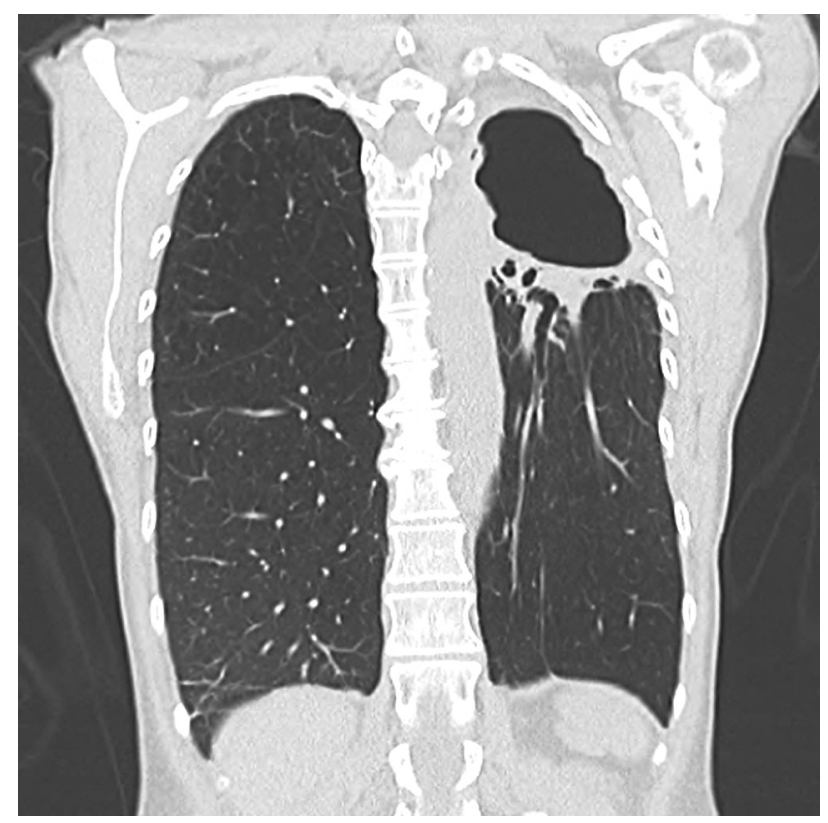

FIGURE 1. Computed tomographic scan showing left upper lobe cavity 5 months before drainage procedure. Signs of infectious disease surrounding the cavity were found on this scan and on computed tomographic scans performed in the preceding 17 months.

fever and leukocytosis and was given intravenous antibiotics. Chest radiography and computed tomography showed a bilateral multifocal pneumonia. Pus culture came positive for methicillin-sensitive Staphylococcus aureus. The patient was discharged 6 days after the intervention with a regimen of intravenous antibiotics to be continued at home.

On follow-up 14 days after drainage, the patient reported no further coughing and sputum production and diminution of pleuritic chest pain.
Bronchoscopy 5 months after the intervention showed a wide-open bronchial opening between the LUL cavity and the airway (Figure 2).

\section{DISCUSSION}

Antibiotic therapy is the typical first-line treatment for lung abscesses. Patients who have no response to prolonged antibiotic therapy most often require percutaneous drainage or surgical intervention. ${ }^{1,2}$ In the case we report, the patient was debilitated and the abscess was in the radiation bed, so she was not considered a good surgical candidate. Percutaneous drainage was not a good option in this case because of the patient's destroyed lobe and lack of pulmonary parenchyma to allow abscess shrinkage and obliteration. This is also why endoscopic placement of a catheter in the abscess was not performed, as described in other case reports with an endoscopic approach to lung abscess treatment. $^{3-5}$ Reopening the airway to permit internal drainage of the abscess was therefore chosen as a minimally invasive next step. We believed that this permanent opening between the cavity and the airway would also reduce the chance of cavity reinfection.

To our knowledge, this is the first report of the use of argon plasma coagulation for endoscopic internal abscess drainage. This technique has the advantage of requiring no contact between the probe and the bronchial wall. Cauterized tissue thus does not stick to the probe as with standard endoscopic electrocautery. In addition, the minimal depth of penetration and the superficial burn associated with argon allows controlled and safe coagulation within the lung tissue.

In conclusion, endoscopic drainage of lung abscesses with argon plasma coagulation is a safe, simple, and effective technique in selected cases. It may be the best or only

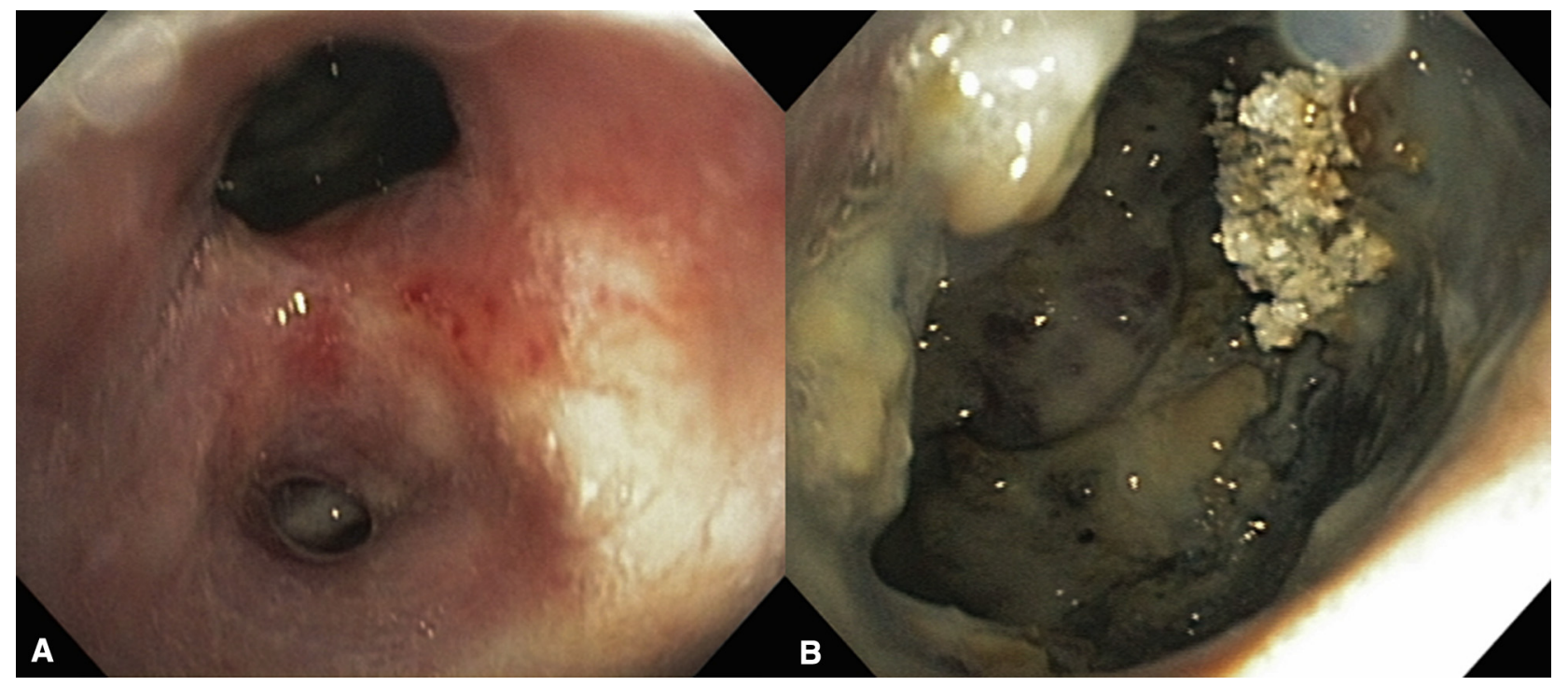

FIGURE 2. A, Patient left apicoposterior segmental bronchus 5 months after initial intervention. B, Left upper lobe cavity 5 months after initial intervention. 
option after failure of medical treatment in certain patients for whom a surgical intervention is prohibitive. Postprocedural pneumonia is a possible complication and should be watched for in postprocedure care.

\section{References}

1. Hagan JL, Hardy JD. Lung abscess revisited. A survey of 184 cases. Ann Surg. 1983;197:755-62.
2. Wali SO. An update on the drainage of pyogenic lung abscesses. Ann Thorac Med 2012;7:3-7.

3. Herth F, Ernst A, Becker HD. Endoscopic drainage of lung abscesses: technique and outcome. Chest. 2005;127:1378-81

4. Schmitt GS, Ohar JM, Kanter KR, Naunheim KS. Indwelling transbronchial catheter drainage of pulmonary abscess. Ann Thorac Surg. 1988;45: 43-7.

5. Shlomi D, Kramer MR, Fuks L, Peled N, Shitrit D. Endobronchial drainage of lung abscess: the use of laser. Scand J Infect Dis. 2010;42:65-8.

\title{
Chest wall reconstruction after resection of a chest wall sarcoma by osteosynthesis with the titanium MatrixRIB (Synthes) system
}

\author{
L. Marleen Boerma, MD, ${ }^{\mathrm{a}}$ Mike Bemelman, MD, ${ }^{\mathrm{b}}$ and Thijs van Dalen, MD, PhD, ${ }^{\mathrm{a}}$ Utrecht, \\ The Netherlands
}

Solid tumors of the chest wall are rare, with soft-tissue sarcomas being the predominant primary malignancy. Wide local excision is the standard operative treatment for soft-tissue sarcomas, but obtaining adequate margins by removal of the tumor en bloc with adjacent ribs results in large defects of the thoracic cage. Today, chest wall resections can be performed with acceptable morbidity and mortality. ${ }^{1}$

Various methods for chest wall reconstruction have been described. The best method should provide stability of the chest, watertight and airtight closure, and acceptable cosmetic appearance. Ideally, it would also be a relative easy procedure. Marlex (Chevron Phillips Chemical Company LP, The Woodlands, Tex) mesh, acrylic cement, polytetrafluoroethylene (Gore-Tex; WL Gore \& Associates, Inc, Flagstaff, Ariz) patches, bone cement, fascia grafts, and silicone implants, alone or in combination, have all been described for this purpose. ${ }^{2}$ All work reasonably well, although none of these solutions fulfill all the described requirements.

Recently, 2 patients underwent a chest wall resection for a soft-tissue sarcoma. In both cases, the chest wall was reconstructed with titanium MatrixRIB system (Synthes $\mathrm{GmbH}$, Zuchwil, Switzerland) plates to bridge the gap between the costal ends.

\footnotetext{
From the Department of Surgery, ${ }^{\mathrm{a}}$ Diakonessenhuis, Utrecht, The Netherlands; and the Department of Surgery, ${ }^{\mathrm{b}}$ University Medical Center, Utrecht, The Netherlands. Disclosures: Authors have nothing to disclose with regard to commercial support. MatrixRIB is a trademark of Synthes GmbH, Zuchwil, Switzerland. L.M.B. and M.B. contributed equally to this article.

Received for publication Jan 3, 2013; revisions received April 27, 2013; accepted for publication May 9, 2013; available ahead of print July 15, 2013.

Address for reprints: Thijs van Dalen, $\mathrm{MD}, \mathrm{PhD}$, Bosboomstraat 1, $3582 \mathrm{KE}$ Utrecht,

The Netherlands (E-mail: tvdalen@diakhuis.nl).

J Thorac Cardiovasc Surg 2013;146:e37-40

$0022-5223 / \$ 36.00$

Copyright (c) 2013 by The American Association for Thoracic Surgery

http://dx.doi.org/10.1016/j.jtcvs.2013.05.010
}

\section{CLINICAL SUMMARIES \\ Patient 1}

A 65-year-old male patient presented with a mass on the trunk. On examination, there was a firm swelling on the right lower dorsolateral aspect of the thorax, fixed on the chest wall. Computed tomographic and magnetic resonance imaging (MRI) scans showed a solid tumor measuring $7 \times 4 \times 6 \mathrm{~cm}$, with paravertebral involvement of ribs 9 , 10, and 11 (Figure 1). Incisional biopsy revealed a softtissue sarcoma, histomorphologically classified as a leiomyosarcoma (grade 2). A resection was done en bloc, with the overlying part of the latissimus dorsi muscle and the involved and adjacent ribs 8 through 11 . The resulting defect was closed with 4 titanium rib plates (MatrixRIB system) to bridge the defects in the respective ribs. The plates were each fixed to the transected ribs with 4 screws

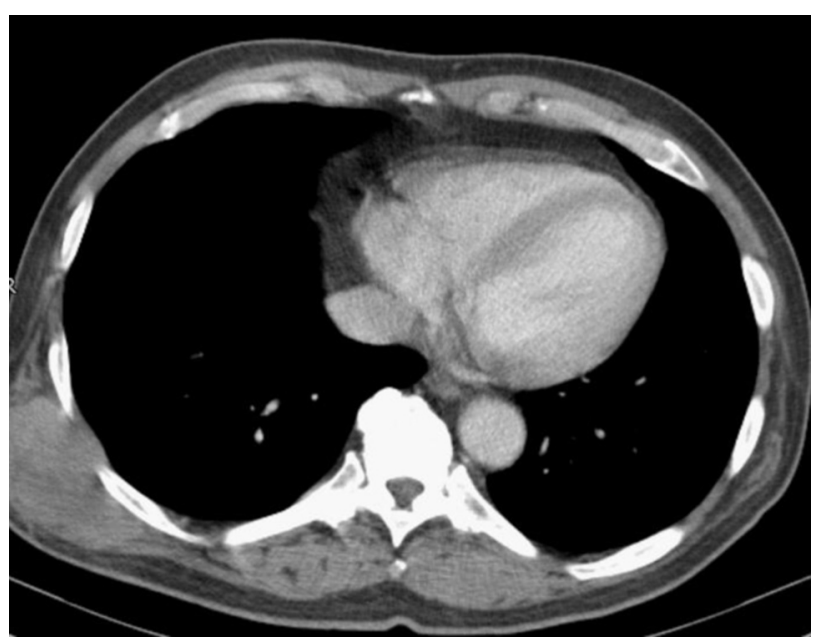

FIGURE 1. Computed tomographic scan shows a $7.2 \times 4.4 \times 6.2 \mathrm{~cm}$ neoplasm in the right dorsal chest wall, with ingrowth in the intercostal space. 